\title{
Spin-Spin Relaxation and Karyagin-Gol'danskii Effect in $\mathrm{FeCl} 3 \cdot 6 \mathrm{H} 2 \mathrm{O}$
}

\author{
Thrane, N.; Trumpy, Georg
}

Published in:

Physical Review B Condensed Matter

Link to article, DOI:

10.1103/PhysRevB.1.153

Publication date:

1970

Document Version

Publisher's PDF, also known as Version of record

Link back to DTU Orbit

Citation (APA):

Thrane, N., \& Trumpy, G. (1970). Spin-Spin Relaxation and Karyagin-Gol'danskii Effect in FeCl3.6H2O. Physical Review B Condensed Matter, 1(1), 153-155. https://doi.org/10.1103/PhysRevB.1.153

\section{General rights}

Copyright and moral rights for the publications made accessible in the public portal are retained by the authors and/or other copyright owners and it is a condition of accessing publications that users recognise and abide by the legal requirements associated with these rights.

- Users may download and print one copy of any publication from the public portal for the purpose of private study or research.

- You may not further distribute the material or use it for any profit-making activity or commercial gain

- You may freely distribute the URL identifying the publication in the public portal

If you believe that this document breaches copyright please contact us providing details, and we will remove access to the work immediately and investigate your claim 


\title{
Spin-Spin Relaxation and Karyagin-Gol'danskii Effect in $\mathrm{FeCl}_{3} \cdot 6 \mathrm{H}_{2} \mathrm{O}$
}

\author{
N. Thrane and G. Trumpy \\ Laboratory of Applied Physics II, Technical University of Denmark, Lyngby, Denmark
}

(Received 4 August 1969)

\begin{abstract}
The Mössbauer spectrum of $\mathrm{FeCl}_{3} \cdot 6 \mathrm{H}_{2} \mathrm{O}$ at room temperature is an anomalously asymmetric quadrupole pattern, which is exceptionally sensitive to external magnetic fields. The asymmetry of the spectrum is diminished both when an external magnetic field is applied and when the temperature is decreased. Qualitatively, the experimental results can be explained by a combination of a temperature- and magnetic-fielddependent spin-spin relaxation and the Karyagin-Gol'danskii effect. This implies that the zero-field splitting is about $20^{\circ} \mathrm{K}$ between the lowest-lying Kramers doublet, found to be the $\left| \pm \frac{1}{2}\right\rangle$, and the other doublets. The fluctuating magnetic field at the Fe sites is found to be directed along the axis of crystal-field symmetry.
\end{abstract}

GEVERAL authors have previously reported Möss$\mathrm{S}$ bauer measurements on $\mathrm{FeCl}_{3} \cdot 6 \mathrm{H}_{2} \mathrm{O}$ and different interpretations of the spectra have been given. ${ }^{1-6}$ In this paper results are presented which were obtained with the absorber in an external magnetic field, and some new conclusions are drawn.

The crystal structure of $\mathrm{FeCl}_{3} \cdot 6 \mathrm{H}_{2} \mathrm{O}$ is known, ${ }^{7}$ each ferric ion being surrounded by two chloride ions and four water molecules, forming an octahedral $\mathrm{Fe}\left(\mathrm{H}_{2} \mathrm{O}\right)_{4^{-}}$ $\mathrm{Cl}_{2}{ }^{+}$ion. This ion has almost axial symmetry, the two chloride ions being placed along the $z$ axis and the four water molecules nearly placed in a square in the $x-y$ plane. The assumption of ionic bonding of the iron atom is supported by measurements of the magnetic susceptibility, ${ }^{3}$ which has a value in agreement with the spin-only value expected for a paramagnetic compound with $\mathrm{Fe}^{3+}$ in the ${ }^{6} S_{5 / 2}$ high-spin state.

Mössbauer spectra ${ }^{8}$ of polycrystalline $\mathrm{FeCl}_{3} \cdot 6 \mathrm{H}_{2} \mathrm{O}$ were obtained at temperatures ranging from 4.2 to $300^{\circ} \mathrm{K}$ and with an external magnetic field up to 0.8 $\mathrm{Wb} / \mathrm{m}^{2}$. The measurements were carried out with an ordinary constant-acceleration Mössbauer drive in connection with a 400-channel multichannel analyzer. $\mathrm{Co}^{57}$ in $\mathrm{Pd}$ was used as a source. Because $\mathrm{FeCl}_{3} \cdot 6 \mathrm{H}_{2} \mathrm{O}$ is very absorbent, it was pulverized in dry-nitrogen atmosphere and placed in a Perspex absorber holder, which was hermetically sealed and covered with silicon grease and an aluminum foil. The condition of the substance was controlled by inspection of the color, as it becomes brownish when water is absorbed.

The spectra obtained are shown in Figs. 1 and 2. As shown by the dashed lines, they have been decomposed by means of graphical methods into two lines, the parameters of which are shown in Table I. Computer decomposition into Lorenzian lines was not applied,

\footnotetext{
1 W. Kerler und W. Neuwirth, Z. Physik 167, 176 (1962).

${ }^{2}$ H. Bernais and M. Langevin, J. Phys. (Paris) 24, 1034 (1963)

${ }_{3}$ P. R. Brady, J. F. Duncan, and K. F. Mok, Proc. Roy. Soc. (London) A287, 343 (1965).

4 J. Danon, in Chemical Applications of Mössbauer Spectroscopy, edited by V. I. Gol'danskii and R. H. Herber (Academic Press Inc., New York, 1968), Chap. 3, p. 246.

5 J. W. G. Wignall, J. Chem. Phys. 44, 2462 (1966).

6 A. J. Nozik and M. Kaplan, J. Chem. Phys. 49, 4141 (1968)

${ }^{7}$ M. D. Lind, J. Chem. Phys. 47, 990 (1967).

${ }^{8} \mathrm{FeCl}_{3} \cdot 6 \mathrm{H}_{2} \mathrm{O}$ pro analysi was obtained from E. Merck AG Darmstadt, Germany.
}

since none of the lines exhibit Lorenzian shape. The spectra obtained at 78,197 , and $300^{\circ} \mathrm{K}$ were obtained with the same absorber and can be mutually compared. At $4.2^{\circ} \mathrm{K}$, another absorber was used and only the quadrupole splitting and the isomer shift should be compared with the other spectra.

Whe spectrum obtained at room temperature is an asymmetric quadrupole pattern consisting of two lines of different shapes. The quadrupole splitting is 0.97 $\mathrm{mm} / \mathrm{sec}$, and the center of the lines indicates an isomer shift of $0.27 \mathrm{~mm} / \mathrm{sec}$ relative to $\mathrm{Fe}$ in $\mathrm{Pd}$. Both values are characteristic for $\mathrm{Fe}^{3+}$ compounds.

A quadrupole-split Mössbauer spectrum of polycrystalline isotropic absorbers can become asymmetric for two reasons: First, the Karyagin-Gol'danskii effect, ${ }^{9,10}$ which is based on the anisotropy of the DebyeWaller factor in connection with the angular distribution of the $\gamma$ radiation, and second, the relaxation of paramagnetic ions causing fluctuating magnetic fields. ${ }^{11,12}$ The former effect will give lines with different areas and equal shapes, while relaxation will result in lines with different shapes and equal areas. Both effects influence the spectra of $\mathrm{FeCl}_{3} \cdot 6 \mathrm{H}_{2} \mathrm{O}$.

We observe a drastic change in the appearance of the spectra when a moderately strong external magnetic field is applied. Without an external field the width of the left-hand line, $\Gamma_{-}$, increases with temperature between 4.2 and $78^{\circ} \mathrm{K}$, while $\Gamma_{+}$(width of the righthand line) remains largely constant. This would indicate an increase of the relaxation time with the temperature. Spin-lattice relaxation times will decrease with increasing temperature, and spin-spin relaxation is essentially temperature-independent. However, Blume $^{13}$ has shown that a temperature-dependent spin-spin relaxation will occur in special cases, as exemplified by ferric hemin, which has a Mössbauer spectrum rather similar to the one of $\mathrm{FeCl}_{3} \cdot 6 \mathrm{H}_{2} \mathrm{O}$.

The ${ }^{6} S_{5 / 2}$ ground state of the $\mathrm{Fe}^{3+}$ ion is split by the crystal field into three Kramers doublets, described by

${ }^{9}$ V. I. Gol'danskii, G. M. Gorodinskii, S. V. Karyagin, L. A. Korytko, L. M. Krizhanskii, E. F. Makarov, I. P. Suzdalev, and V. V. Krapov, Dokl. Akad. Nauk SSSR 147, 127 (1962).

${ }^{10}$ S. V. Karyagin, Dokl. Akad. Nauk SSSR 148, 1102 (1963).

${ }^{11}$ M. Blume, Phys. Rev. Letters 14, 96 (1965)

${ }_{12}$ M. Blume and J. A. Tjon, Phys. Rev. 165, 446 (1968).

${ }^{13}$ M. Blume, Phys. Rev. Letters 18, 305 (1967). 
TABLE I. Parametersa of the two lines obtained by graphical decomposition of the Mössbauer spectra of polycrystalline $\mathrm{FeCl}_{3} \cdot 6 \mathrm{H}_{2} \mathrm{O}$.

\begin{tabular}{|c|c|c|c|c|c|c|c|c|c|}
\hline \multirow{2}{*}{$\begin{array}{l}\text { Tem- } \\
\text { perature } \\
B\end{array}$} & \multirow{2}{*}{$\begin{array}{c}\left({ }^{\circ} \mathrm{K}\right) \\
\mathrm{Wb} / \mathrm{m}^{2}\end{array}$} & \multicolumn{2}{|c|}{300} & \multicolumn{2}{|c|}{197} & \multicolumn{2}{|c|}{78} & \multicolumn{2}{|c|}{$4.2^{\mathrm{b}}$} \\
\hline & & 0 & 0.8 & 0 & 0.8 & 0 & 0.8 & $0^{\mathrm{T} .}$ & 0.6 \\
\hline$\Delta E_{Q}$ & $\mathrm{~mm} / \mathrm{sec}$ & 0.97 & 0.97 & 0.93 & 0.93 & 0.91 & 0.91 & 0.91 & $\ldots$ \\
\hline$\delta$ & $\mathrm{mm} / \mathrm{sec}$ & 0.27 & 0.27 & 0.34 & 0.34 & 0.42 & 0.42 & 0.36 & $\ldots$ \\
\hline$P_{+}$ & $\%$ & 7.7 & 7.9 & 10.5 & 10.9 & 15.1 & 17.7 & 14.7 & $\cdots$ \\
\hline$P_{-}^{+}$ & & 3.8 & 7.5 & 5.5 & 10.5 & 8.5 & 16.4 & 14.6 & $\ldots$ \\
\hline$\Gamma_{+}^{-}$ & $\mathrm{mm} / \mathrm{sec}$ & 0.45 & 0.45 & 0.45 & 0.45 & 0.45 & 0.44 & 0.68 & $\ldots$ \\
\hline$\Gamma_{-}^{+}$ & $\mathrm{mm} / \mathrm{sec}$ & 1.06 & 0.59 & 1.05 & 0.60 & 1.16 & 0.59 & 0.84 & $\ldots$ \\
\hline$A_{+}$ & arbitrary unit & 146 & 145 & 199 & 198 & 286 & 308 & 306 & $\ldots$ \\
\hline$A_{-}^{+}$ & arbitrary unit & 145 & 177 & 207 & 243 & 353 & 382 & 363 & $\ldots$ \\
\hline$A_{+}+A_{-}$ & arbitrary unit & 291 & 321 & 403 & 438 & 642 & 684 & 667 & 736 \\
\hline$A_{-}^{+} / A_{+}$ & & 1.00 & 1.22 & 1.04 & 1.23 & 1.23 & 1.24 & 1.19 & $\cdots$ \\
\hline
\end{tabular}

a Quadrupole splitting $\Delta E_{Q}$, isomer shift $\delta$, line amplitude $P$, linewidth $\Gamma$, and line area $A$; the subscripts + and - refer to the positively and the negatively situated line, respectively.

$S_{2}= \pm \frac{5}{2}, \pm \frac{3}{2}$, and $\pm \frac{1}{2}$. The relaxation between the different ionic states produces a time-dependent magnetic field at the nucleus. The relaxation time between the $\left|+\frac{1}{2}\right\rangle$ and $\left|-\frac{1}{2}\right\rangle$ states is much shorter than between the other states. At sufficiently low temperatures only the lowest Kramers doublet is populated, and as the relaxation time is increased with

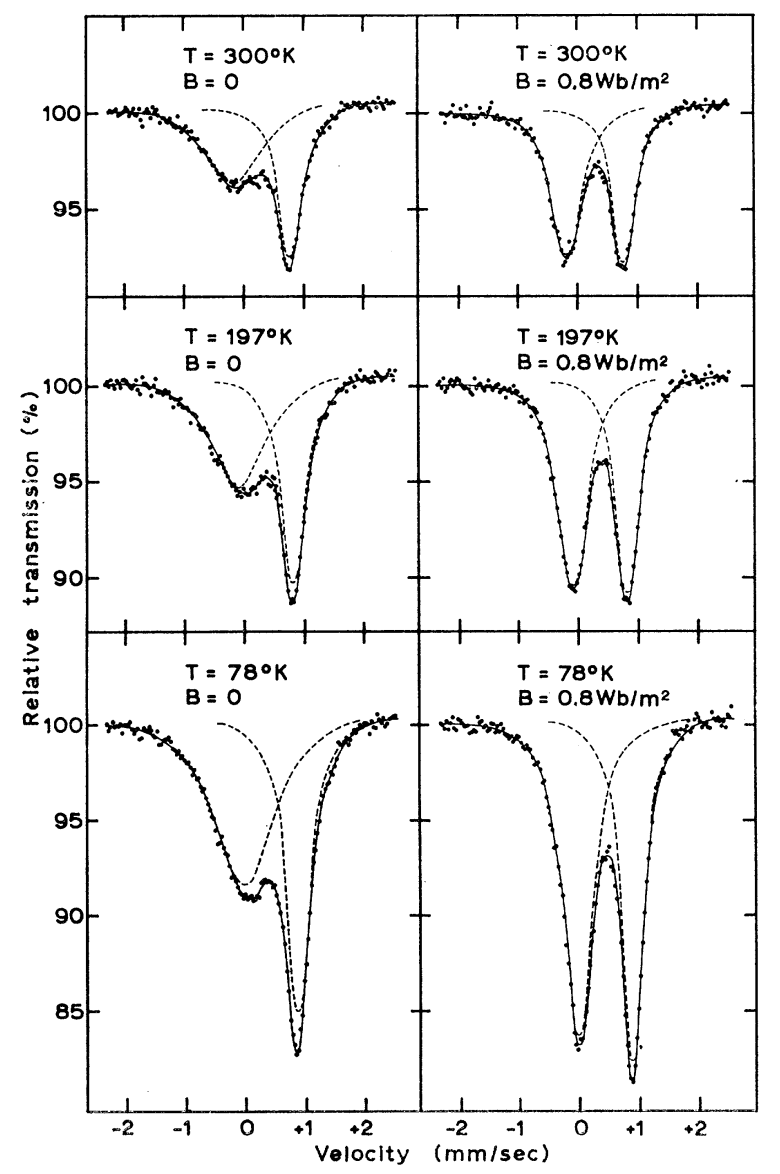

FIG. 1. Mössbauer spectra of polycrystalline $\mathrm{FeCl}_{3} \cdot 6 \mathrm{H}_{2} \mathrm{O}$ at different temperatures and with an applied external magnetic field of 0 and $0.8 \mathrm{~Wb} / \mathrm{m}^{2}$. the temperature, we can conclude that the $\left| \pm \frac{1}{2}\right\rangle$ doublet lies below $\left| \pm \frac{3}{2}\right\rangle$ and $\left| \pm \frac{5}{2}\right\rangle$.

Qualitatively this mechanism can explain the observed temperature dependence of the spectra, provided that the zero-field splitting between the $\left| \pm \frac{1}{2}\right\rangle$ doublet and the other doublets is of the order of $20^{\circ} \mathrm{K}$. This is a rather great splitting for an $S$-state ion, but not unreasonable. In ferric hemin this splitting is $18^{\circ} \mathrm{K}$.

The direction of the fluctuating magnetic field can be deduced when the electric-field-gradient (EFG) tensor is known. A Mössbauer spectrum obtained by Johnson $^{14}$ at $4.2^{\circ} \mathrm{K}$, in an external magnetic field of $3 \mathrm{~Wb} / \mathrm{m}^{2}$, showed a six-line pattern from which it was found that the quadrupole constant $e^{2} q Q$ is negative. Here, $Q$ is the nuclear quadrupole moment and $e q=V_{z z}$ is the EFG tensor component along the $z$ axis. Accordingly, the lowest-energy line in our quadrupole split spectra corresponds to the $\left| \pm \frac{3}{2}\right\rangle \rightarrow\left| \pm \frac{1}{2}\right\rangle$ nuclear transition. In the cases of asymmetry, this is also the line with the larger width, given by $\Gamma_{-}$in Table I.

A broadening or splitting of a narrow line will result when the relaxation time of the magnetic field is comparable to or larger than the nuclear Larmor period.

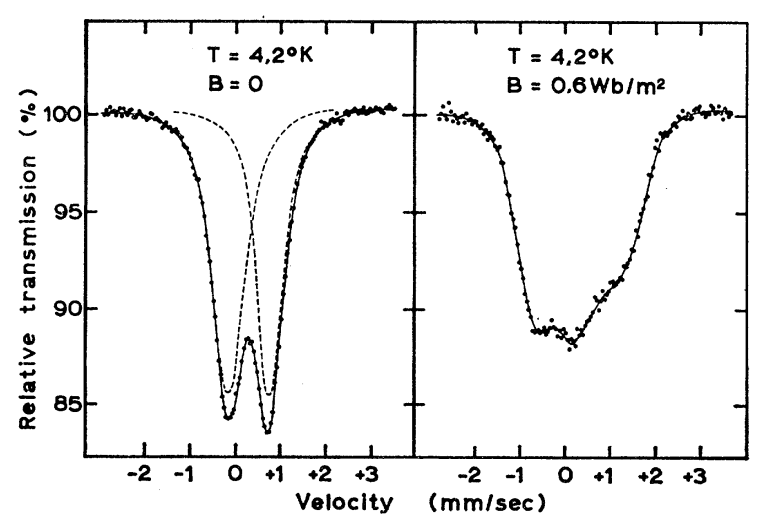

FIG. 2. Mössbauer spectra of polycrystalline $\mathrm{FeCl}_{3} \cdot 6 \mathrm{H}_{2} \mathrm{O}$ at $4.2^{\circ} \mathrm{K}$ with an applied external magnetic field of 0 and $0.6 \mathrm{~Wb} / \mathrm{m}^{2}$.

${ }^{14}$ C. E. Johnson, in Proceedings of the Conference on Application of the Mössbauer Effect, Tihany, Hungary, 1969 (to be published). 
If this field is directed along the $z$ axis, it is easy to see that the $\pm \frac{3}{2}$ nuclear level can be broadened while the $\pm \frac{1}{2}$ level is narrow. In the more complicated case in which the field is transverse to the $z$ axis, Blume and Tjon $^{12}$ have shown that the width asymmetry will be inversed.

We therefore conclude that the fluctuating magnetic field in paramagnetic $\mathrm{FeCl}_{3} \cdot 6 \mathrm{H}_{2} \mathrm{O}$ is directed along the symmetry axis of the crystal field at the $\mathrm{Fe}^{3+}$ ion.

As seen in Fig. 1 and Table I an external magnetic field of moderate strength causes a considerable narrowing of the broad line, corresponding to a reduced spinspin relaxation time. This magnetic field dependence is not in contradiction with theory because of the crystalfield splitting of the ionic levels. ${ }^{15}$

It could be argued that a reduction of the left-hand linewidth $\Gamma_{-}$will result when the external field is applied perpendicular to the $z$ axis, because of the anisotropy of the $g$ factor for the $\left| \pm \frac{1}{2}\right\rangle$ ionic state $\left(g_{11}=2\right.$, $\left.g_{\perp}=6\right)$. $\Gamma_{-}$then decreases while $\Gamma_{+}$increases. As our absorber is polycrystalline, an applied external field might cause a narrowing of the left-hand line and simultaneously a broadening of the right one.

However, as no such broadening of the right-hand line is observed by application of the external field, we conclude that the field dependence of the relaxation time is the predominant effect.

Apart from the asymmetry in the linewidth, the spectra of $\mathrm{FeCl}_{3} \cdot 6 \mathrm{H}_{2} \mathrm{O}$ also exhibit a marked asymmetry in line area (integral line intensity). We wish to point out that it is important to distinguish between these two kinds of difference in line shape. ${ }^{16}$ In the present case relaxation effects alone could not cause a difference in the integral intensities of the two lines. We therefore conjecture that these observed area asymmetries are rather caused by the KaryaginGol'danskii effect for the case of a polycrystalline absorber.

Table I shows that the ratio between the left- and right-hand line areas is about 1.2 for all cases when both

${ }^{15} \mathrm{~J}$. Caspers, Theory of Spin Relaxation (Wiley-Interscience, Inc., New York, 1964), Chap. II, p. 108.

${ }^{16}$ Concerning asymmetric Mössbauer spectra, one should distinguish between line amplitude and line area (integral intensity). The word "intensity," often used to describe such lines, has no unambiguous meaning in this connection. lines are fairly narrow. When the left line is broad, the area ratio is apparently smaller. However, under the above assumptions, line broadening by relaxation, we know that the central part of such a line is accompanied by an extremely broad line, the area of which easily can be up to $20-30 \%$ of the total area. As this broad line has a very small amplitude, it will be hidden in the observed base line, i.e., our base line has been placed too low. A shift upwards on only $\frac{1}{2}$ per thousand is sufficient to supply the necessary areas. A Mössbauer spectrum obtained at $300^{\circ} \mathrm{K}$ without external field in the velocity range $\pm 10 \mathrm{~mm} / \mathrm{sec}$ and with $4 \times 10^{6}$ counts per channel indeed showed a slight slope of the base line, which can be attributed to the broad line.

Therefore, the area asymmetry may well have a constant value given by $A_{-} / A_{+}=1.22 \pm 0.05$, roughly independent of temperature and of external magnetic fields.

An asymmetric Debye-Waller factor is very likely in view of the structure of $\mathrm{FeCl}_{3} \cdot 6 \mathrm{H}_{2} \mathrm{O}$. Lind ${ }^{7}$ finds the rms values of the thermal vibration of the $\mathrm{Fe}$ atom along the principal axes $i, j, k$ of the thermal vibration ellipsoid to be $0.15,0.16,0.18 \AA$, respectively, where the $i$ axis is nearly coincident with the $z$ axis, and the $j-k$ plane with the $x-y$ plane. This means that the ratio between the Mössbauer probabilities along $i, j$, and $k$ axes is approximately $0.30: 0.25: 0.18$. As the Mössbauer probability is largest along the $z$ axis, and as the $\gamma$-ray angular distribution of the $\left| \pm \frac{3}{2}\right\rangle \rightarrow\left| \pm \frac{1}{2}\right\rangle$ nuclear transition has its maximum along the $z$ axis, one should expect the Mössbauer intensity of this transition to be the largest. This is consistent with the observed area asymmetry.

At $4.2^{\circ} \mathrm{K}$ a broadening of the spectrum is observed when the external magnetic field is applied. At this low temperature the relaxation time is short and only the lowest ionic level $\left| \pm \frac{1}{2}\right\rangle$ is populated. The magnetic splitting is comparable with the temperature and the levels will therefore be unequally populated, which results in an effective magnetic field at the nucleus. The spectrum will be quite complicated because the sample is polycrystalline, causing a mixture of the ionic states, and because the $g$ factor of $\left| \pm \frac{1}{2}\right\rangle$ state is anisotropic. Furthermore, the relaxation time might not be short enough to avoid an additional broadening of the spectrum. 